\title{
Systemic Autoimmune Diseases in Patients with Hepatitis C Virus Infection: Characterization of 1020 Cases (The HISPAMEC Registry)
}

\author{
MANUEL RAMOS-CASALS, SANDRA MUÑOZ, FRANCISCO MEDINA, LUIS-JAVIER JARA, JOSÉ ROSAS, \\ JAIME CALVO-ALEN, PILAR BRITO-ZERÓN, XAVIER FORNS, and JOSE-MARIA SÁNCHEZ-TAPIAS, \\ for the HISPAMEC Study Group
}

ABSTRACT. Objective. To describe the clinical and immunologic characteristics of a large series of patients with systemic autoimmune diseases (SAD) associated with chronic hepatitis C virus (HCV) infection.

Methods. The HISPAMEC Registry is a multicenter international study group dedicated to collecting data on patients diagnosed with SAD with serological evidence of chronic HCV infection. The information sources are cases reported by physicians of the HISPAMEC Study Group and periodic surveillance of reported cases by a Medline search updated up to December 31, 2007.

Results. One thousand twenty HCV patients with SAD were included in the registry. Patients were reported from Southern Europe (60\%), North America (15\%), Asia (14\%), Northern Europe (9\%), South America (1\%), and Australia (1\%). Countries reporting the most cases were Spain (236 cases), France (222 cases), Italy (144 cases), USA (120 cases), and Japan (95 cases). The most frequently reported SAD were Sjögren's syndrome (SS; 483 cases), rheumatoid arthritis (RA; 150 cases), systemic lupus erythematosus (SLE; 129 cases), polyarteritis nodosa (78 cases), antiphospholipid syndrome (59 cases), inflammatory myopathies (39 cases), and sarcoidosis ( 28 cases). Twenty patients had 2 or more SAD. Epidemiological data were available in 677 cases. Four hundred eighty-seven (72\%) patients were female and $186(28 \%)$ male, with a mean age of $49.5 \pm 1.0$ years at SAD diagnosis and $50.5 \pm 1.1$ years at diagnosis of $\mathrm{HCV}$ infection. The main immunologic features were antinuclear antibody (ANA) in $61 \%$ of patients, rheumatoid factor (RF) in $57 \%$, hypocomplementemia in $52 \%$, and cryoglobulins in $52 \%$. The main differential aspect between primary and HCV-related $\mathrm{SAD}$ was the predominance of cryoglobulinemic-related markers (cryoglobulins, RF, hypocomplementemia) over specific SAD-related markers (anti-ENA antibodies, anti-dsDNA, anti-cyclic citrullinated peptide) in patients with $\mathrm{HCV}$.

Conclusion. In the selected cohort, the SAD most commonly reported in association with chronic HCV infection were SS (nearly half the cases), RA and SLE. Nearly two thirds of SAD-HCV cases were reported from the Mediterranean area. In these patients, ANA, RF and cryoglobulins are the predominant immunological features. (First Release April 15 2009; J Rheumatol 2009;36:1442-8; doi:10.3899/jrheum.080874)

Key Indexing Terms:

HEPATITIS C VIRUS SJÖGREN'S SYNDROME

RHEUMATOID ARTHRITIS

ANTIPHOSPHOLIPID SYNDROME

\section{SYSTEMIC LUPUS ERYTHEMATOSUS POLYARTERITIS NODOSA LYMPHOMA}

The hepatitis $\mathrm{C}$ virus (HCV) is a linear, single-stranded RNA virus of the Flaviviridae family that was identified in 1989 and is recognized as the major causal agent of non-A,
non-B hepatitis ${ }^{1}$. The global prevalence of $\mathrm{HCV}$ infection has been estimated at nearly $3 \%$, with a substantial geographic variation ${ }^{2}$. The lowest prevalence rates for $\mathrm{HCV}$
From the Laboratory of Autoimmune Diseases “Josep Font," Department of Autoimmune Diseases, Institut d'Investigacions Biomèdiques August Pi $i$ Sunyer (IDIBAPS), Hospital Clínic, Barcelona, Spain; Department of Rheumatology, Hospital de Especialidades, Centro Médico Nacional Siglo XXI and Centro Médico Nacional La Raza, Mexico DF, Mexico

Rheumatology Unit, Hospital de la Vila-Joiosa, Vila-Joiosa, Alacant; Rheumatology Unit, Hospital de Sierrallana, Santander; and Liver Unit, Institut d'Investigacions Biomèdiques August Pi i Sunyer (IDIBAPS), Hospital Clínic, Barcelona, Spain.

Supported by Grant FIS 04/0701.

M. Ramos-Casals, MD, PhD; S. Muñoz, MD, Laboratory of Autoimmune Diseases “Josep Font," Department of Autoimmune Diseases, Institut d'Investigacions Biomèdiques August Pi i Sunyer (IDIBAPS); F. Medina,
MD, Department of Rheumatology, Hospital de Especialidades, Centro Médico Nacional Siglo XXI; L-J. Jara, MD, Centro Médico Nacional La Raza; J. Rosas, MD, PhD, Rheumatology Unit, Hospital de la Vila-Joiosa; J. Calvo-Alen, MD, PhD, Rheumatology Unit, Hospital de Sierrallana; P. Brito-Zerón, MD, PhD, Laboratory of Autoimmune Diseases “Josep Font," Department of Autoimmune Diseases, Institut d'Investigacions Biomèdiques August Pi i Sunyer (IDIBAPS); X. Forns, $M D, P h D ; J-M$. Sánchez-Tapias, $M D, P h D$, Liver Unit, Institut d'Investigacions Biomèdiques August Pi $i$ Sunyer (IDIBAPS). Address reprint requests to Dr. M. Ramos-Casals, Servei de Malalties Autoimmunes, Hospital Clínic, C/Villarroel, 170, 08036-Barcelona, Spain.E-mail:mramos@clinic.ub.es

Accepted for publication January 16, 2009. Personal non-commercial use only. The Journal of Rheumatology Copyright @ 2009. All rights reserved. 
infection in blood donors has been reported in Northern Europe $(<0.01 \%)$, followed by the USA and Western Europe $(0.2 \%-0.5 \%)$ and South America, Eastern Europe and the Mediterranean area (1\%-5\%), with Egypt having the highest prevalence rate $(>15 \%)^{3}$. However, these prevalence rates determined from blood donors probably underestimate $\mathrm{HCV}$ prevalence in the general population ${ }^{3}$, and a US national survey found a prevalence 4-fold higher in the general population than in volunteer blood donors $(1.8 \%$ vs $0.4 \%$, respectively $)^{4,5}$.

A decade ago, various investigators described the association of HCV infection with a heterogeneous group of "nonhepatic" conditions, such as pulmonary fibrosis, cutaneous vasculitis, glomerulonephritis, Mooren ulcers, and porphyria cutanea tarda or lichen planus ${ }^{6}$, which have since been considered "extrahepatic" manifestations of $\mathrm{HCV}$ infection, although it is currently accepted that a weak degree of association exists in some of them. Cryoglobulinemia was the first systemic autoimmune disease (SAD) clearly associated with $\mathrm{HCV}$, and several groups reported that $>80 \%$ of patients with cryoglobulinemia had HCV infection ${ }^{7,8}$. The association between HCV and other SAD is less clear, and there is growing interest in the possible relationships, especially with Sjögren's syndrome (SS), rheumatoid arthritis (RA), systemic lupus erythematosus (SLE), systemic vasculitis, and sarcoidosis ${ }^{9,10}$. However, a differing degree of association has been described for each SAD, possibly related to the variations in the overlap between extrahepatic $\mathrm{HCV}$ features and those included in the current classification criteria of the different SAD.

The aims of our study were to describe the clinical and immunological expression of HCV patients with SAD and to analyze the percentage of each individual criterion fulfilled by these patients for each SAD.

\section{MATERIALS AND METHODS}

Patients. The Hispanoamerican Study Group of Autoimmune Manifestations associated with Hepatitis C Virus (HISPAMEC) is a multicenter study group consisting of various reference centers with substantial experience in the management of SAD and chronic HCV infection. A protocol form was designed to record the clinical and serologic characteristics of patients diagnosed with SAD who had serological evidence of chronic $\mathrm{HCV}$ infection (at least 2 positive determinations by a third-generation ELISA and/or positive HCV-RNA by polymerase chain reaction), with the aim of creating a registry of patients with SAD associated with chronic $\mathrm{HCV}$ infection. HCV patients with "primary" cryoglobulinemia (not associated with other SAD) are excluded. The information sources are cases reported by physicians of the HISPAMEC Study Group and periodic surveillance of reported cases by a Medline search updated up to December 31,2007 . The criteria for including cases identified in the literature search were the same as those applied to patients reported by HISPAMEC physicians (serological evidence of chronic HCV infection and fulfillment of the current classification criteria of the corresponding SAD). Only cases in which sufficient reliable information was available were included.

To minimize possible interobserver bias, the inclusion criteria and variables of the protocol were agreed on by all the participating physicians. Information collected by protocol forms was transferred to a computerized database program (SPSS for Windows; SPSS, Chicago, IL, USA). The pro- tocol included written consent from patients and conformed to the ethical standards currently applied in the different centers involved.

Definition of clinical features. Salient features included in the protocol form were: (1) sex; (2) age at diagnosis of SAD, defined as the age when the patient fulfilled the current criteria for the classification of the respective SAD; (3) age at diagnosis of chronic $\mathrm{HCV}$ infection, defined as the first serological evidence of positive HCV antibodies; (4) classification criteria fulfilled for the respective SAD; (5) cumulative hepatic and extrahepatic manifestations; and (6) laboratory findings. Due to the retrospective study design, the data are presented as patients having the feature/patients in whom the feature was studied.

The diagnosis of SAD was based on the following classification criteria: (1) SS according to the preliminary diagnostic criteria proposed in 1993 by the European Community Study Group ${ }^{11}$; (2) SLE according to the revised criteria of the American College of Rheumatism (ACR) ${ }^{12}$; (3) RA according to the ACR criteria $^{13}$; (4) systemic sclerosis according to the ACR preliminary criteria ${ }^{14}$; (5) polymyositis-dermatomyositis according to the Bohan and Peter criteria ${ }^{15}$; (6) primary antiphospholipid syndrome (APS) according to the preliminary classification criteria ${ }^{16}$; and (7) systemic vasculitis according to the consensus nomenclature proposed by Jennette, et $a l^{17}$.

\section{RESULTS}

General characteristics. One thousand twenty HCV patients with SAD were included in the registry (last update December 31, 2007). Patients were reported from Southern Europe (60\%), North America (15\%), Asia (14\%), Northern Europe (9\%), South America (1\%), and Australia (1\%). The countries reporting the most cases were Spain (236 cases), France (222 cases), Italy (144 cases), USA (120 cases), and Japan (95 cases; Table 1).

The most frequent reported SAD were SS (483 cases),

Table 1. Countries reporting 1020 cases of SAD-HCV included in the HISPAMEC Registry.

\begin{tabular}{lc}
\hline Country & Patients, $\mathrm{n}(\%)$ \\
\hline Spain & $236(23.27)$ \\
France & $222(21.76)$ \\
Italy & $144(14.11)$ \\
USA & $120(11.76)$ \\
Japan & $95(9.31)$ \\
Russia & $44(4.31)$ \\
Mexico & $34(3.33)$ \\
Germany & $30(2.94)$ \\
Israel & $27(2.64)$ \\
China & $21(2.05)$ \\
Hungary & $13(1.27)$ \\
Portugal & $7(0.68)$ \\
Turkey & $6(0.58)$ \\
Poland & $6(0.58)$ \\
Greece & $3(0.29)$ \\
Rumania & $3(0.29)$ \\
Sweden & $2(0.19)$ \\
Australia & $2(0.19)$ \\
Columbia & $1(0.09)$ \\
India & $1(0.09)$ \\
Holland & $1(0.09)$ \\
Switzerland & $1(0.09)$ \\
Belgium & $1(0.09)$ \\
\hline
\end{tabular}

Personal non-commercial use only. The Journal of Rheumatology Copyright @ 2009 . All rights reserved. 
RA (150 cases), SLE (129 cases), polyarteritis nodosa (PAN; 78 cases), APS (59 cases), inflammatory myopathies (39 cases), and sarcoidosis (28 cases; Table 2). In addition to the corresponding $\mathrm{SAD}, 10$ patients had lichen planus and 2 porphyria cutanea tarda. Twenty patients had 2 or more SAD. Epidemiological data were available in 677 cases. Four hundred eighty-seven (72\%) patients were female and 186 (28\%) male, with a mean age of $49.5 \pm 1.0$ years at SAD diagnosis and $50.5 \pm 1.1$ years at diagnosis of HCV infection. The main immunologic features were antinuclear antibodies (ANA) in $61 \%$ of patients, rheumatoid factor (RF) in $57 \%$, hypocomplementemia in $52 \%$, and cryoglobulins in $52 \%$ (Table 3). There were 16 patients with HBV coinfec-

Table 2. Systemic autoimmune disease (SAD) in patients with HCV infection: cases included in the HISPAMEC Registry.

\begin{tabular}{lc}
\hline SAD & Patients, $\mathrm{n}(\%)$ \\
\hline Sjögren syndrome & $483(47.5)$ \\
Rheumatoid arthritis & $150(14.7)$ \\
Systemic lupus erythematosus & $129(12.6)$ \\
Polyarteritis nodosa & $78(7.6)$ \\
Antiphospholipid syndrome & $59(5.8)$ \\
Inflammatory myopathies & $39(3.8)$ \\
Sarcoidosis & $28(2.7)$ \\
Systemic sclerosis & $11(1.1)$ \\
Behçet disease & $10(<1)$ \\
Temporal arteritis & $7(<1)$ \\
ANCA-glomerulonephritis & $5(<1)$ \\
Urticaria-vasculitis & $4(<1)$ \\
Ankylosing spondylitis & $3(<1)$ \\
Wegener granulomatosis & $3(<1)$ \\
Churg-Strauss vasculitis & $2(<1)$ \\
Henoch-Schönlein purpura & $2(<1)$ \\
Central nervous system vasculitis & $1(<1)$ \\
Relapsing polychondritis & $1(<1)$ \\
Microscopic polyangiitis & $1(<1)$ \\
Polymyalgia rheumatica & $1(<1)$ \\
Mixed connective tissue disease & $1(<1)$ \\
Takayasu arteritis & $1(<1)$ \\
Goodpasture syndrome & $1(<1)$ \\
Total & $1020(100)$ \\
\hline &
\end{tabular}

tion (all with PAN) and 10 with HIV coinfection (6 with PAN, 2 with APS, and 2 with inflammatory myopathy).

Seventy-five SAD-HCV patients included in the registry developed neoplasia, most frequently hematological (42 cases, 35 of which were B cell lymphoma) and hepatocellular carcinoma (16 cases). Five patients developed 2 neoplasias.

SS-HCV. There were 483 patients with SS-HCV included in the registry $(79 \%$ women, mean age $53.6 \pm 1.5$ yrs at SS diagnosis and 55.2 $\pm 1.1 \mathrm{yrs}$ at diagnosis of $\mathrm{HCV}$ ). Patients fulfilled the following SS criteria: xerophthalmia in 430/440 (97\%) patients, xerostomia in $427 / 440$ (97\%), positive Schirmer test in 236/242 (98\%), altered rose Bengal staining in $13 / 14(93 \%)$, altered salivary flow in $21 / 26(81 \%)$, positive salivary scintigraphy in $135 / 159(85 \%)$, positive salivary gland biopsy in 191/259 (74\%), ANA in 181/266 (68\%), RF in 130/243 (53\%), and anti-Ro/La in 69/269 $(25 \%)$.

SLE-HCV. There were 129 patients with SLE-HCV $(85 \%$ women, mean age $39 \pm 3.4$ yrs at SLE diagnosis and $40.1 \pm$ $2.6 \mathrm{yrs}$ at HCV diagnosis). Patients fulfilled the 1997 SLE criteria $^{12}$ : ANA in $123 / 125(98 \%)$ patients, arthritis in $87 / 102$ (85\%), positive anti-dsDNA in $86 / 105$ (82\%), cytopenias in 70/120 (69\%), malar rash in $65(62 \%)$, positive antiphospholipid antibodies (aPL) in 54/115 (47\%), nephropathy in $43 / 102(43 \%)$, positive anti-Sm in $16 / 43$ (37\%), oral ulcers in 31/102 (30\%), serositis in $29 / 102$ (29\%), photosensitivity in $26 / 102(25 \%)$, neurologic involvement in 8/102 (8\%), and discoid lupus in $2(2 \%)$.

$R A-H C V$. There were 150 patients with RA-HCV $(76 \%$ women, mean age $53 \pm 3.2$ yrs at RA diagnosis and $57 \pm 2.2$ $\mathrm{yrs}$ at $\mathrm{HCV}$ diagnosis). Features in the RA classification criteria were arthritis of more than 3 articular areas in 109/111 (98\%), arthritis of hands 106/111 (95\%), symmetric arthritis 106/111 (95\%), positive RF 110/111 (99\%), radiographic changes 98/111 (89\%), morning stiffness 74/111 (67\%), and rheumatoid nodules 8/111 (7\%).

$P A N-H C V$. Seventy-eight patients were diagnosed with PAN ( $41 \%$ women, mean age $44 \pm 3.6 \mathrm{yrs}$ at PAN diagnosis and

Table 3. Immunological markers in patients with SAD-HCV.

\begin{tabular}{lcccc}
\hline SAD & $\begin{array}{c}\text { Antinuclear Antibody, } \\
\text { Positive/total (\%) }\end{array}$ & $\begin{array}{c}\text { Rheumatoid Factor, } \\
\text { Positive/total (\%) }\end{array}$ & $\begin{array}{c}\text { Hypocomplementemia, } \\
\text { Positive/total (\%) }\end{array}$ & $\begin{array}{c}\text { Cryoglobulinemia, } \\
\text { Positive/total (\%) }\end{array}$ \\
\hline Sjögren syndrome & $181 / 266(68)$ & $130 / 243(53)$ & $107 / 212(50)$ & $147 / 314(47)$ \\
Rheumatoid arthritis & $23 / 43(53)$ & $110 / 111(99)$ & $30 / 55(55)$ & $13 / 38(34)$ \\
Systemic lupus erythematosus & $123 / 125(98)$ & $14 / 44(32)$ & $77 / 110(70)$ & $50 / 87(58)$ \\
Polyarteritis nodosa & $2 / 8(25)$ & $21 / 40(52)$ & $19 / 45(42)$ & $24 / 48(50)$ \\
Antiphospholipid syndrome & $5 / 15(33)$ & $6 / 16(38)$ & $9 / 16(56)$ & $7 / 16(44)$ \\
Inflammatory myopathies & $9 / 17(53)$ & $1 / 13(8)$ & $8 / 15(13)$ & $3 / 18(17)$ \\
Other systemic vasculitis & $5 / 20(25)$ & $4 / 19(21)$ & $0 / 10(0)$ & $17 / 25(68)$ \\
Systemic sclerosis & $9 / 10(90)$ & $5 / 10(50)$ & $0 / 8(0)$ & $2 / 10(20)$ \\
Sarcoidosis & $2 / 8(25)$ & $1 / 8(13)$ & $0 / 3(0)$ & $1 / 9(11)$ \\
Other diseases & $2 / 4(50)$ & $2 / 4(50)$ & & $2 / 3(67)$ \\
\hline
\end{tabular}

Personal non-commercial use only. The Journal of Rheumatology Copyright @ 2009 . All rights reserved. 
$42 \pm 3.7 \mathrm{yrs}$ at HCV diagnosis). Patients fulfilled the classification criteria of PAN: necrotizing inflammation of medium or small arteries in biopsy specimens in 54/57 (95\%) patients, livedo reticularis 35/57 (61\%), weight loss $34 / 57$ (60\%), polyneuropathy $34 / 57$ (60\%), myalgias or weakness $33 / 57$ (58\%), altered arteriography 28/57 (49\%), hypertension 21/57 (37\%), raised creatinine 15/57 (26\%) and positive HBsAg in 15/57 (26\%). No patient presented with testicular involvement.

APS-HCV. There were 59 patients with APS-HCV $(46 \%$ women, mean age $47 \pm 2.6$ yrs at APS diagnosis and $49 \pm$ $2.5 \mathrm{yrs}$ at diagnosis of $\mathrm{HCV}$ ). Patients fulfilled the following criteria for APS: positive aPL in $59(100 \%)$ patients, thrombosis in $51(87 \%)$, and fetal losses in $9(14 \%)$.

Inflammatory myopathies-HCV. There were $39 \mathrm{HCV}$ patients with inflammatory myopathies (59\% women, mean age $52 \pm 2.1$ yrs at diagnosis of inflammatory myopathies and $49 \pm 2.5 \mathrm{yrs}$ at diagnosis of HCV). Patients fulfilled the following classification criteria for inflammatory myopathies: myopathic changes on electromyography 34/34 (100\%), proximal muscle weakness 33/34 (97\%), increased serum concentrations of muscle enzymes 33/34 (97\%), histopathological findings consistent with inflammatory myositis in 33/34 (97\%), and skin lesions suggestive of dermatomyositis in 13/34 (38\%).

Sarcoidosis-HCV. There were $28 \mathrm{HCV}$ patients with sarcoidosis unrelated to antiviral therapy (70\% women, mean age $50 \pm 4.76 \mathrm{yrs}$ at diagnosis of sarcoidosis and $54 \pm 3.75$ yrs at diagnosis of HCV). Twenty out of $24(83 \%)$ patients presented respiratory symptoms, 10/24 (42\%) cutaneous involvement, extrapulmonary adenopathies in 12/24 (50\%; cervical in 8 , supraclavicular in 3 , inguinal in 2 , abdominal in 1), articular involvement in 3/24 (13\%) patients, renal involvement in $1 / 24(4 \%)$, and parotid gland involvement in 2/24 (7\%).

Other $S A D-H C V$. The remaining 54 patients, with SAD-HCV, presented different diseases, of which systemic sclerosis $(\mathrm{n}=$ 11), Behçet disease $(n=10)$, Horton disease $(n=7)$, and antineutrophil cytoplasmic antibody (ANCA)-glomerulonephritis $(\mathrm{n}=5)$ were the most frequent (Table 2).

\section{DISCUSSION}

Viruses are often proposed as etiologic or triggering agents of SAD. HCV is the chronic viral infection most frequently related to the development of autoimmune processes, both clinical and immunological. The specific tropism of $\mathrm{HCV}$ for many extrahepatic cell types, as reported ${ }^{8}$, provides the basis for a link between HCV and the development of extrahepatic manifestations.

Although nearly $40 \%$ of unselected patients with $\mathrm{HCV}$ have at least one clinical or analytical extrahepatic feature ${ }^{18}$, the prevalence of patients fulfilling SAD criteria is much lower $(2 \%-6 \%)$. For this reason, the HISPAMEC Registry has compiled data for $1020 \mathrm{HCV}$ patients with coexisting $\mathrm{SAD}$, which has allowed characterization of the clinical expression of SAD in patients with chronic HCV infection. The most frequent SAD included in the HISPAMEC Registry, representing $90 \%$ of cases, are SS, SLE, RA, and PAN. Other SAD, such as systemic sclerosis, inflammatory myopathies, sarcoidosis and ANCA-related vasculitis, are uncommon. These data, together with those from series of SAD patients tested for HCV infection ${ }^{19}$, confirm the predominant association of HCV with specific SAD.

The majority of studies reporting analysis of the prevalence of chronic HCV infection in patients with SAD found a higher prevalence than that in the general population. However, these prevalences vary widely according to geographic area ${ }^{20}$. The best example is SS: studies from southern Europe describe a prevalence of HCV infection in SS patients between $10 \%$ and $20 \%$, while studies from Scandinavia and the US ${ }^{21,22}$ found a prevalence $<1 \%$, probably due to the lower prevalence of HCV infection in these countries $^{23}$. Seventy percent of all reported cases of SAD in patients with $\mathrm{HCV}$ infection come from 3 Mediterranean countries (Spain, France, and Italy), underlining this geographic variability.

Currently, SS should be considered the SAD most closely associated with $\mathrm{HCV}$, first because recent experimental evidence in mice ${ }^{24}$ and humans ${ }^{25}$ supports the sialotropism of $\mathrm{HCV}^{26}$, and second, because clinical evidence shows that SS is the SAD with the highest prevalence of chronic HCV infection, which was detected in $151(18 \%)$ of the 858 SS patients tested ${ }^{27}$. In the HISPAMEC Registry, SS accounts for $47 \%$ of the SAD associated with HCV. Analysis of these cases has identified a considerable overlap between SS classification criteria and extrahepatic features of HCV infection, especially with respect to sicca syndrome (both subjective and objective), histopathological criteria, and immunological markers such as ANA and RF. This shows that a clinical diagnosis of SS could easily be made in patients with $\mathrm{HCV}$ presenting with sicca syndrome and positive ANA and/or RF. In contrast, positive antiRo/La antibodies were described in only $25 \%$ of patients with SS-HCV, a prevalence that is half that found in primary $\mathrm{SS}^{28}$. This suggests that the main differential aspect between primary and HCV-related SS is the immunological pattern, with a predominance of cryoglobulin-related markers (mixed cryoglobulins, RF, hypocomplementemia) over SS-related markers (anti-Ro/SSA and anti-La/SSB autoantibodies) ${ }^{29}$. In addition, we recently found a 3-fold higher prevalence of hypocomplementemia in patients with SS-HCV compared with patients with primary $\mathrm{SS}^{30}$. Other studies have found a close association between SS and HCV. Sicca syndrome was the second most frequent extraglandular manifestation in the largest series of unselected HCV patients reported ${ }^{31}$, with a prevalence of $11 \%$. In another study, SS was diagnosed in $5 \%$ of 147 unselected $\mathrm{HCV}$ patients, a prevalence 5-fold

Personal non-commercial use only. The Journal of Rheumatology Copyright (c) 2009. All rights reserved. 
greater than that of the general population ${ }^{32}$. Finally, Caporali, et $a l^{33}$ recently found that $15 \%$ of 501 patients in whom salivary gland biopsy was carried out due to a clinical suspicion of SS were HCV-positive.

With respect to SLE, chronic HCV infection can induce clinical and serologic features that together can meet the ACR 1997 revised criteria for SLE ${ }^{12}$. First, some clinical criteria such as arthritis and glomerulonephritis may be observed in HCV patients, especially in the context of associated cryoglobulinemia. Second, cytopenias such as thrombocytopenia and leukopenia are also frequently found in patients with $\mathrm{HCV}$. Third, unselected HCV patients have a higher prevalence of some immunological markers included in the SLE criteria, such as ANA and aPL (nearly $20 \%{ }^{18}$ ), and even low to moderate titers of anti-dsDNA antibodies ${ }^{34}$. In contrast, other SLE criteria have been described rarely in HCV patients with extrahepatic involvement (SLE-related cutaneous features, oral ulcers, central nervous system involvement, hemolytic anemia, anti-Sm antibodies, and high titers of anti-dsDNA) ${ }^{35}$. However, since some patients with SLE-HCV do present these features, we suggest that this subset of patients should be considered as having true coexistence of SLE and chronic HCV infection. Although the pathogenic role of $\mathrm{HCV}$ infection in these patients is unclear, it is possible that $\mathrm{HCV}$ acts as a triggering factor in some patients with a specific genetic background.

It is understandable that $\mathrm{HCV}$ patients presenting with polyarthritis and positive RF could be clinically classified as having RA. Of the current ACR classification criteria, there are 4 (arthritis of $\geq 3$ joint areas, arthritis of hand joints, symmetric arthritis, and serum RF) that are usually found in patients with $\mathrm{HCV}$ infection. In 3 series that analyzed 75 HCV patients with arthritis ${ }^{36-38}$, nearly half fulfilled the ACR criteria for RA. Cryoglobulinemia (which causes arthritis and is associated with positive RF) plays a significant role in the overlap between extrahepatic HCV features and RA criteria, making the differentiation between cryoglobulinemic arthritis and HCV-related RA difficult. Erosive arthritis in HCV patients should be considered as highly specific for a true coexistence between HCV and RA, since cryoglobulinemic arthritis is overwhelmingly nonerosive $^{37,38}$. In addition, recent studies have focused on the potential role of antibodies to cyclic citrullinated peptides $(\mathrm{CCP})$ in differentiating between RA and cryoglobulinemicrelated arthritis in patients with chronic $\mathrm{HCV}$ infection. Wener, et $a l^{39}$ found no anti-CCP antibodies in $\mathrm{HCV}$ patients, although some false-positive results were observed in patients with cryoglobulinemia, while Bombardieri, et $a l^{40}$ found anti-CCP antibodies in $76 \%$ of patients with RA and in $60 \%$ of those with RA and HCV, but found none in $\mathrm{HCV}$ patients without RA. Sène, et $a l^{32}$ investigated the diagnostic reliability of anti-CCP antibodies in distinguishing $\mathrm{HCV}$-associated rheumatologic manifestations from RA and found that anti-CCP antibodies were the most specific biological marker for RA, with a specificity of $93 \%$ and a positive predictive value of $96 \%$. These studies strongly suggest that anti-CCP antibodies may discriminate $\mathrm{HCV}$ patients with true RA from those with $\mathrm{HCV}$-associated arthritis.

Cryoglobulinemic-HCV patients may present several features such as weight loss, myalgia or weakness, peripheral neuropathy, elevated blood urea nitrogen/creatinine, and positive HBV markers that are included in the 1990 classification criteria for PAN. However, histopathological analysis can easily differentiate PAN from cryoglobulinemia, the 2 types of systemic vasculitis most frequently associated with HCV infection. PAN shows necrotizing inflammation of medium-size arteries in contrast to the leukocytoclastic vasculitis found in cryoglobulinemia. The remaining reported cases of systemic vasculitis in patients with $\mathrm{HCV}$ infection included isolated reports of giant cell arteritis, ANCA-related vasculitides, and Henoch-Schönlein purpura, but they were few in number, in contrast to about 80 reported cases of PAN-HCV. The 1990 criteria for these systemic vasculitides show a slight overlap with the most common extrahepatic HCV features, and their coexistence with $\mathrm{HCV}$ infection may be considered a chance phenomenon. Anecdotally, there are 2 reported cases of cryoglobulinemic vasculitis mimicking giant cell arteritis ${ }^{41,42}$, although careful analysis of histologic data led to correct diagnosis in both cases.

Cryoglobulinemia is the key immunological marker of SAD associated with HCV. Clinically, cryoglobulinemicrelated features such as general malaise, fever, myalgia, vasculitis, arthritis, neuropathy, and glomerulonephritis may easily lead to fulfillment of classification criteria for some SAD (especially SLE, RA, and PAN) in HCV patients. In addition, the immunological profile of patients with $\mathrm{HCV}$-related SAD is characterized by a clear predominance of cryoglobulinemic-related markers (cryoglobulins, RF, hypocomplementemia) over specific SAD-related markers (anti-extractable nuclear antigen, anti-dsDNA, anti-CCP). A very careful application of the current classification criteria for SAD in patients with chronic HCV infection is strongly recommended. However, current criteria for SAD were in fact validated without control groups of patients with chronic viral infections, making it impossible to ascertain whether these criteria may be useful in distinguishing the mimicking of a SAD by extrahepatic HCV manifestations, the coexistence of the 2 processes based on a common etiopathogenic basis, or a casual association of 2 prevalent processes. Indeed, there are criteria from some diseases (i.e., PAN) that include a chronic viral infection, while in others (such as SS) chronic viral infections are excluded. Future revisions of classification criteria may ideally include as controls not only healthy controls, but also patients with prevalent nonautoimmune diseases such as neoplasia or chronic viral infections.

Personal non-commercial use only. The Journal of Rheumatology Copyright $@$ C 2009. All rights reserved. 
Few studies have systematically investigated SAD in unselected populations of patients with HCV. Only 2 studies $^{18,43}$ performed a complete evaluation of SAD in a total of 411 unselected HCV patients, finding that SS ( $\mathrm{n}=$ $10)$, PAN $(\mathrm{n}=9)$, and SLE $(\mathrm{n}=6)$ were the 3 most frequently identified SAD. Two additional studies ${ }^{32,44}$ specifically investigated SS in a total of 216 unselected HCV patients, and found that $11(5 \%)$ fulfilled classification criteria for SS, a prevalence 5 to 10 -fold greater than that described in the general population. These data show results similar to those from our registry.

Unlike epidemiological studies, our results offer a different viewpoint on the association between $\mathrm{HCV}$ and SAD, utilizing a registry of consecutive HCV patients who fulfilled classification criteria for $\mathrm{SAD}$, a methodological approach that did not allow us to establish whether the degree of association between $\mathrm{HCV}$ and the different SAD was strong or weak. This explains why the prevalence of SS in large series of patients with $\mathrm{HCV}^{31,32,45}$ ranges between $5 \%$ and $10 \%$ while in our registry SS represents $47 \%$. In addition, there was a selection bias in some SAD. Thus, the high frequency of SS may be related to patient selection bias in the centers participating in the HISPAMEC and SS-HCV study groups (from Spain, Italy, France, and Mexico), most of whom are referral centers for SS. Of the 483 cases of SS included in the registry, 145 (30\%) came from the study groups. A similar bias related to a specific interest in a specific SAD may also be observed in groups working in vasculitis $^{18,31}$ and $\mathrm{RA}^{36-39}$. Due to the study design, our results do not allow the assumption that patients with SAD-HCV included in our registry are representative of the frequency of the different SAD in the general HCV population, which makes it impossible to calculate the comparative prevalence of the SAD in patients with and without $\mathrm{HCV}$ infection.

We describe the main characteristics of a registry of 1020 patients with coexisting SAD and chronic HCV infection. Using these cumulative data, it cannot be determined whether there is an etiopathogenic association between HCV infection and SAD or whether the simultaneous diagnosis may be coincidental. However, it is notable that SS, SLE, RA, and PAN accounted for $80 \%$ of the total reported SAD-HCV cases. Given the significant overlap between extrahepatic HCV features and the current classification criteria for these $\mathrm{SAD}$, we recommend that these criteria should be reevaluated to take the influence of HCV-related features into account.

\section{ACKNOWLEDGMENT}

The authors thank David Buss for his editorial assistance.

Members of the Hispanoamerican Study Group of Extrahepatic Manifestations of Hepatitis C Virus (HISPAMEC): M. Ramos-Casals (Coordinator), P. Brito-Zerón, S. Muñoz, Laboratory of Autoimmune Diseases "Josep Font," Department of Autoimmune Diseases, Hospital Clinic, IDIBAPS, Barcelona, Spain; X. Forns, J.M. Sanchez-Tapias, Liver Unit, IDIBAPS, Hospital Clinic, Barcelona; A. López-Guillermo, Department of Hematology, Hospital Clinic, Barcelona; J. Rosas, G.
Santos, Rheumatology Unit, Hospital de la Vila-Joiosa, Vila-Joiosa, Alacant, Spain; F. Medina, Department of Rheumatology, Hospital de Especialidades, Centro Médico Nacional Siglo XXI, Mexico DF, Mexico; L.J. Jara, Department of Rheumatology, Hospital de Especialidades, Centro Médico Nacional La Raza, Mexico DF, Mexico; J.M. Anaya, Rheumatology Unit, Corporación para Investigaciones Biológicas and Clínica Universitaria Bolivariana, School of Medicine, Universidad Pontificia Bolivariana, Medellín, Colombia; J.C. Restrepo, Hospital Pablo Tobón Uribe and University of Antioquia, Medellín; J. Mañá, Department of Internal Medicine, Hospital Universitari de Bellvitge, Hospitalet de Llobregat, Barcelona, Spain.

\section{REFERENCES}

1. Choo QL, Kuo G, Weiner AJ, Overby LR, Bradley DW, Houghton $\mathrm{M}$. Isolation of a cDNA clone derived from a blood borne non-A, non-B viral hepatitis genome. Science 1989;244:359-62.

2. Alter MJ, Mast EE. The epidemiology of viral hepatitis in the United States. Gastroenterol Clin North Am 1994;23:437-55.

3. Yen T, Keeffe EB, Ahmed A. The epidemiology of hepatitis C virus infection. J Clin Gastroenterol 2003;36:47-53.

4. Alter MJ, Kruszon-Moran D, Nainan OV, et al. The prevalence of hepatitis C virus infection in the United States, 1988 through 1994. N Engl J Med 1999;341:556-62.

5. Glynn SA, Kleinman SH, Schreiber GB, et al. Trends in incidence and prevalence of major transfusion-transmissible viral infections in US blood donors, 1991 to 1996. Retrovirus Epidemiology Donor Study (REDS). JAMA 2000;284:229-35.

6. Gumber SC, Chopra S. Hepatitis C: a multifaceted disease. Review of extrahepatic manifestations. Ann Intern Med 1995;123:615-20.

7. Ferri C, Greco F, Longombardo G, et al. Antibodies to hepatitis C virus in patients with mixed cryoglobulinemia. Arthritis Rheum 1991;34:1606-10.

8. Marcellin P, Descamps V, Martinot-Peignoux M, et al. Cryoglobulinemia with vasculitis associated with hepatitis $\mathrm{C}$ virus infection. Gastroenterology 1993;104:272-7.

9. Haddad J, Deny P, Munz-Gotheil C, et al. Lymphocytic sialadenitis of Sjögren's syndrome associated with chronic hepatitis $\mathrm{C}$ virus liver disease. Lancet 1992;339:321-3.

10. Ramos-Casals M, Forns X, Sánchez-Tapias JM, Rodés J. Extrahepatic manifestations of HCV infection. In: Font J, Ramos-Casals M, Rodés J, editors. Digestive involvement in systemic autoimmune diseases. Amsterdam: Elsevier; 2008.

11. Vitali C, Bombardieri S, Moutsopoulos HM, et al. Preliminary criteria for the classification of Sjogren's syndrome. Arthritis Rheum 1993;36:340-7.

12. Hochberg MC. Updating the American College of Rheumatology revised criteria for the classification of systemic lupus erythematosus [letter]. Arthritis Rheum 1997;40:1725.

13. Arnett FC, Edworthy SM, Bloch DA, et al. The American Rheumatism Association 1987 revised criteria for the classification of rheumatoid arthritis. Arthritis Rheum 1988;31:315-24.

14. Anonymous. Preliminary criteria for the classification of systemic sclerosis (scleroderma). Subcommittee for scleroderma criteria of the American Rheumatism Association Diagnostic and Therapeutic Criteria Committee. Arthritis Rheum 1980;23:581-90.

15. Bohan A, Peter JB. Polymyositis and dermatomyositis. N Engl J Med 1975;292:344-47.

16. Wilson WA, Gharavi AE, Koike T, et al. International consensus statement on preliminary classification criteria for definite antiphospholipid syndrome. Arthritis Rheum 1999;42:1309-11.

17. Jennette JC, Falk RJ, Andrassy K, et al. Nomenclature of systemic vasculitides. Proposal of an international consensus conference. Arthritis Rheum 1994;37:187-94.

18. Cacoub P, Renou C, Rosenthal E, et al. Extrahepatic manifestations

Personal non-commercial use only. The Journal of Rheumatology Copyright @ 2009. All rights reserved. 
associated with hepatitis $\mathrm{C}$ virus infection. A prospective multicenter study of 321 patients. Medicine (Baltimore) 2000;79:47-56.

19. Ramos-Casals M, Font J, Ingelmo M. Prevalence and clinical significance of hepatitis $\mathrm{C}$ virus infection in systemic autoimmune diseases. Med Clin (Barc) 2001;116:701-9.

20. Ramos-Casals M, Font J. Extrahepatic manifestations in patients with chronic hepatitis $\mathrm{C}$ virus infection. Curr Opin Rheumatol 2005; 17:447-55.

21. Verbaan H, Carlson J, Eriksson S, et al. Extrahepatic manifestations of chronic hepatitis $\mathrm{C}$ infection and the interrelationship between primary Sjogren's syndrome and hepatitis C in Swedish patients. J Intern Med 1999;245:127-32.

22. King PD, McMurray RW, Becherer PR. Sjogren's syndrome without mixed cryoglobulinemia is not associated with hepatitis C virus infection. Am J Gastroenterol 1994;89:1047-50.

23. Ramos-Casals M, Jara LJ, Medina F, et al; HISPAMEC Study Group. Systemic autoimmune diseases co-existing with chronic hepatitis $\mathrm{C}$ virus infection (the HISPAMEC Registry): Patterns of clinical and immunological expression in 180 cases. J Intern Med 2005;257:549-57.

24. Koike K, Moriya K, Ishibashi K, et al. Sialadenitis histologically resembling Sjögren syndrome in mice transgenic for hepatitis $\mathrm{C}$ virus envelope genes. Proc Natl Acad Sci USA 1997;94:233-6.

25. Arrieta JJ, Rodriguez-Inigo E, Ortiz-Movilla N, et al. In situ detection of hepatitis $\mathrm{C}$ virus RNA in salivary glands. Am J Pathol 2001;158:259-64.

26. Ramos-Casals M, Garcia-Carrasco M, Cervera R, Font J. Is hepatitis C virus a sialotropic virus? Am J Pathol 2001;159:1593-4.

27. Ramos-Casals M, Loustaud-Ratti V, Zeher M. Hepatitis C virus and autoimmune diseases. In: Ramos-Casals M, Garcia-Carrasco M, Rosas J, Calvo J, Font J, editors. Enfermedades autoinmunes sistémicas y reumatológicas. Barcelona: Ed. Masson; 2005:742-58.

28. Ramos-Casals M, Solans R, Rosas J, et al. Primary Sjögren syndrome in Spain. Clinical and immunologic expression of 1010 patients (The GEMESS Cohort). Medicine (Baltimore) 2008;87:210-9.

29. Ramos-Casals M, Loustaud-Ratti V, De Vita S, et al. Sjogren syndrome associated with hepatitis $\mathrm{C}$ virus: A multicenter analysis of 137 cases. Medicine (Baltimore) 2005;84:81-9.

30. Ramos-Casals M, Brito-Zeron P, Yague J, et al.

Hypocomplementaemia as an immunological marker of morbidity and mortality in patients with primary Sjogren's syndrome. Rheumatology 2005;44:89-94.

31. Cacoub P, Poynard T, Ghillani P, et al. Extrahepatic manifestations of chronic hepatitis C. MULTIVIRC Group. Multidepartment Virus C. Arthritis Rheum 1999;42:2204-12.

32. Sene D, Ghillani-Dalbin P, Limal N, et al. Anti-cyclic citrullinated peptide antibodies in hepatitis $\mathrm{C}$ virus associated rheumatological manifestations and Sjogren's syndrome. Ann Rheum Dis
2006;65:394-7.

33. Caporali R, Bonacci E, Epis O, Bobbio-Pallavicini F, Morbini P, Montecucco C. Safety and usefulness of minor salivary gland biopsy: Retrospective analysis of 502 procedures performed at a single center. Arthritis Rheum 2008;59:714-20.

34. Perlemuter G, Cacoub P, Sbai A, et al. Hepatitis C virus infection in systemic lupus erythematosus: a case-control study. J Rheumatol 2003;30:1473-8.

35. Ramos-Casals M, Font J, Garcia-Carrasco M, et al. Hepatitis C virus infection mimicking systemic lupus erythematosus: Study of hepatitis $\mathrm{C}$ virus infection in a series of 134 Spanish patients with systemic lupus erythematosus. Arthritis Rheum 2000;43:2801-6.

36. Lovy MR, Starkebaum G, Uberoi S. Hepatitis C infection presenting with rheumatic manifestations: a mimic of rheumatoid arthritis. J Rheumatol 1996;23:979-83.

37. Rivera J, García-Monforte A, Millan J. Extrahepatic symptoms as presenting manifestations of hepatitis $\mathrm{C}$ virus infection. J Clin Rheumatol 1999;5:268-72.

38. Ueno Y, Kinoshita R, Tsujinoue H, Kato M. A case of hepatitis C virus (HCV)-associated arthritis. Quantitative analysis of $\mathrm{HCV}$ RNA of the synovial fluid and the serum. Br J Rheumatol 1995;34:691-2.

39. Wener MH, Hutchinson K, Morishima C, Gretch DR. Absence of antibodies to cyclic citrullinated peptide in sera of patients with hepatitis $\mathrm{C}$ virus infection and cryoglobulinemia. Arthritis Rheum 2004;50:2305-8.

40. Bombardieri M, Alessandri C, Labbadia G, et al. Role of anti-cyclic citrullinated peptide antibodies in discriminating patients with rheumatoid arthritis from patients with chronic hepatitis $\mathrm{C}$ infection-associated polyarticular involvement. Arthritis Res Ther 2004;6:R137-41

41. Genereau T, Martin A, Lortholary O, Noel V, Guillevin L. Temporal arteritis symptoms in a patient with hepatitis $\mathrm{C}$ virus associated type II cryoglobulinemia and small vessel vasculitis. J Rheumatol 1998;25:183-5

42. Lamprecht P, Gause A, Gross WL. Cryoglobulinemic vasculitis resistant to intermittent intravenous pulse cyclophosphamide therapy. Scand J Rheumatol 2000;29:201-2.

43. Buskila D, Shnaider A, Neumann L, et al. Musculoskeletal manifestations and autoantibody profile in 90 hepatitis $\mathrm{C}$ virus infected Israeli patients. Semin Arthritis Rheum 1998;28:107-13.

44. D'Amico E, Palazzi C, Cacciatore P, et al. Anti-ENA antibodies in patients with chronic hepatitis $\mathrm{C}$ virus infection. Dig Dis Sci 2002;47:755-9.

45. Barrett S, Goh J, Coughlan B, et al. The natural course of hepatitis $\mathrm{C}$ virus infection after 22 years in a unique homogenous cohort: spontaneous viral clearance and chronic HCV infection. Gut 2001;49:423-30. 